\title{
Alcohol, smoking, folic acid and multivitamin use among women attending maternity care in London: a cross-sectional study
}

Word count: 4281

Number of tables: 5

Number of figures: 0

\section{ABSTRACT (247)}

Objectives: This study describes the patterns of change in health behaviours that pregnant women adopt before and during pregnancy.

Study design: A cross-sectional survey of pregnant women asked questions about pregnancy planning, health knowledge, and health behaviour. Analysis was descriptive with associations examined using logistic regression models.

Main outcome measures: health behaviours before and during pregnancy (smoking, alcohol consumption, and folic acid and multivitamin (supplement) intake), and recall of healthcare professional advice.

Results: 1173 women completed the survey (mean age $32 \pm 5$ years, $68 \%$ white) of whom $73 \%$ indicated that their pregnancy was highly planned. $38 \%$ of women reported having never smoked, $45 \%$ quit smoking before becoming pregnant, and fewer $(5 \%, 95 \% \mathrm{Cl} 3-6 \%)$ reported currently smoking. Current smokers reported reduced cigarette consumption compared to pre-pregnancy, and higher recall of health professional information. Nine percent $(95 \% \mathrm{Cl} 5-8 \%)$ reported currently drinking, reducing the number of units consumed from 6 units weekly before pregnancy (IQR 2-10) to 1 unit weekly during pregnancy (IQR $1-2, p<0.001)$. Most (62\%) women were currently taking supplements, of whom $81 \%$ reported daily use. Women with more planned pregnancies had higher odds of adopting healthier behaviours of stopping smoking or drinking before pregnancy compared to those who stopped during pregnancy or continued the behaviour.

Conclusions: Most women adopted one or more healthy behaviours during pregnancy, with a small minority continuing to smoke or drink alcohol. For women who continued smoking in pregnancy and recalled information from health professionals, additional tailored approaches need to be explored.

Keywords: pregnancy; folic acid; vitamins, smoking; alcohol drinking; health behaviour 


\section{Introduction}

A growing body of scientific literature confirms the short and long term effects of negative health behaviours in pregnancy on the women and the foetus $(1,2)$. Smoking directly affects the placenta causing foetal morbidity and mortality (1) and women are advised to stop smoking or cut down on cigarette consumption in preparation for, or during, their pregnancy (2). The current UK guidelines advise women to completely abstain from alcohol (3) as a dose-response relationship has been identified between alcohol consumption and adverse foetal outcomes including risks of foetal alcohol syndrome, low birth weight, and preterm birth (4). Folic acid is advised for up to three months pre-pregnancy and for the duration of the first trimester, whilst multivitamins are recommended throughout pregnancy (2) and their preventive benefits against congenital abnormalities are well documented (5-7).

Prevalence data of these health behaviours are variable, and a key source of UK national figures is the Infant Feeding Survey, which was previously conducted every five years. The survey quotes prevalence of pregnancy behaviours including breastfeeding, smoking, alcohol consumption, and supplement intake derived from over 10,000 mothers randomly selected from the birth register. The most recent survey in 2010 (8) reported the lowest proportion of negative health behaviours with $12 \%$ of mothers continuing to smoke throughout their pregnancy and $40 \%$ drinking alcohol during pregnancy. Regarding supplements, $94 \%$ of women reported taking folic acid at some point in their pregnancy and $64 \%$ took vitamin or iron supplements during pregnancy.

During pregnancy, the majority of women report receiving healthcare professional information regarding smoking or drinking, with midwives being the commonest source (8). Attempts to show the impact of healthcare professional information has been mixed (9-11) and studies have identified antenatal care as a key intervention point (4). One suggestion has been to argue that the key to optimising the care provided is by entering a "mutually respectful dialogue"(12).

Smoking status at time of delivery was previously one of the few routinely collated national indicators ${ }^{1}$ in the UK which specifically looks at pregnancy health behaviour. This has been transformed by the Maternity Services Dataset (13), a national patient level data set that records key clinical information from the maternity care pathway. This dataset obtains health behaviour data from the booking episode and consequently there remains a gap in knowledge about how women change health behaviours during pregnancy

Although some degree of intention or planning for pregnancy is quite common $(14,15)$, most women regard the health aspects of pregnancy as something to consider if and when, rather than before, they become pregnant (16). Hence, the objective of our study is to describe the changes in health behaviours during pregnancy and to examine sociodemographic disparities between women who engage in certain positive and negative health behaviours.

\section{METHODS}

\section{Design, setting and participants}

A cross-sectional study was carried out across three maternity services in North London Hospitals between November 2011 and May 2012. Detailed methods are reported elsewhere (11). In brief, the hospitals were selected to enable women from diverse ethnic and socioeconomic backgrounds

\footnotetext{
${ }^{1}$ NHS Digital collects The Smoking Status at Time of Delivery (SATOD) indicator which is quarterly collated and includes the number of women smoking and not smoking at time of delivery (child birth). Accessible here: [http://content.digital.nhs.uk/datacollections/ssatod]
} 
to participate. Women attending maternity services at these sites represented a mix of high and low risk pregnancies. Using convenience sampling, women were approached by trained researchers while waiting for their antenatal appointment, with a preference to sample women early in their pregnancy to reduce recall bias.

Participants were given an information leaflet with details of the project and the consent process, and then invited to consent to completing the questionnaire. Women self-completed a pen-andpaper questionnaire and the data were entered onto computer by a commercial data entry company (Abacus).

\section{Questionnaire and measures}

The development of the questionnaire is described in detail elsewhere (11). Briefly, a literature review was conducted to explore themes and topics were considered for inclusion in a questionnaire, which was supplemented by questionnaires previously used by other maternal health research groups $(17,18)$. The questionnaire was co-developed with the Margaret Pyke Forum, a user group that includes members of the public and patients of various ages and backgrounds, and then piloted with five pregnant women attending a maternity service in London. The final questionnaire consisted of 82 items in five domains: health knowledge pre-pregnancy, health knowledge and behaviours during pregnancy, feelings about pre-pregnancy healthcare provision, past medical history, and demographic data.

Current smoking during pregnancy was ascertained by the question 'Are you a smoker now?' (Yes/No) asked of women answering 'Yes' to the question 'Have you ever smoked?'. Current smokers were then asked if they smoked in the three months before pregnancy (Yes/No/No, stopped in preparation for pregnancy). The number of cigarettes smoked daily was asked of women smoking at three months before pregnancy, and women smoking at the time of the survey. Women who had stopped smoking during pregnancy were asked the gestation (in weeks) at which they stopped smoking.

Current alcohol drinking during pregnancy, was ascertained by the question 'Do you drink alcohol now?' (Yes/No) and asked only to participants answering 'Yes' to the question 'Have you ever drunk alcohol?'. The number of alcohol units drunk during the week and weekend was collected by free text spaces for those drinking at three months before pregnancy and for those drinking at the time of the survey. For those who had stopped drinking alcohol during pregnancy, they were asked the gestation (in weeks) at which they stopped drinking. Finally, all women who had ever drunk were asked to recall the number of binges (defined as greater than five drinks in one sitting) they had during their pregnancy, to include the weeks before they knew they were pregnant (free text number/I don't remember or I don't know).

Women were asked about supplement intake during pregnancy, ascertained by the question 'Have you taken any folic acid or multivitamins for women trying to get pregnant (e.g. Pregnacare) while you've been pregnant?' (Yes, folic acid/Yes, multivitamins for women trying to get pregnant/No). They were also asked when they started taking them (before pregnancy, or free text space for gestation in weeks), at what frequency (everyday/most days/occasionally/other), whether they were still taking them (yes/no), or the gestation at which they stopped taking them.

Women were asked about whether they had received information about positive health behaviours from health professionals (defined as GP or other healthcare professional) relating to smoking, alcohol and folic acid/multivitamins. 
We also collected sociodemographic data about age, ethnicity (white/mixed/Asian/black/Chinese/other), education (higher degree/first degree/diploma/A levels/GCSE/other/none), obstetric history (live births, miscarriages, stillbirths or terminations), medication use three months prior to or since pregnancy, and the extent of pregnancy planning. The extent of pregnancy planning was measured using the London Measure of Unplanned Pregnancy, (LMUP), a six-item self-completion questionnaire with established psychometric properties that scores pregnancy planning or intention from 0-12 (19). Scores of 0 to 3 were categorised as 'unplanned,' 4 to 9 as 'ambivalent' and 10 to 12 as 'planned.' Due to small numbers in categories, the ethnicity variable was collapsed into two (white/non-white) and the education variable was collapsed into four (degree/diploma or A level/GCSE or other/none).

\section{Statistical analyses}

The data were managed by determining the extent of missing and invalid data entries for key primary outcome and independent variables. Missing and invalid data entries were subsequently excluded from further analysis. In several observations, a range for units of alcohol or number of cigarettes was submitted rather than numbers; in these instances, they were converted into a mean.

Demographic data, and data on smoking, alcohol and supplement uptake are presented as frequencies and percentages, with $95 \%$ confidence intervals $(\mathrm{Cl})$. For skewed continuous variables such as gestation, number of cigarettes, or units of alcohol, the median and inter-quartile range (IQR) are presented. Changes in behaviours are descriptively reported in four categories: never, quit before pregnancy, quit during pregnancy, or currently adopting the health behaviour. Differences in skewed continuous variables were tested using the Wilcoxon rank-sum (Mann-Whitney U, for independent data) or Wilcoxon Signed-Rank test (for paired data).

Associations between independent variables (age, ethnicity, education, obstetric history, medication use, and pregnancy planning score) and health behaviours were analysed using chi squared tests. Due to small numbers in some categories, women who stopped the behaviour before pregnancy were compared to the collapsed category of those who stopped during pregnancy grouped with those who continued the behaviour. All independent variables were entered into a logistic regression model and were eliminated using a backward stepwise approach at the $p=0.05$ level. Logistic regression models reported adjusted odds ratios (AOR) with $95 \% \mathrm{Cls}$. Finally, forced logistic regression models tested the association between recall of healthcare professional (HP) advice and the collapse behavioural measures, and these were presented as unadjusted and adjusted (for all independent variables) odds ratios with $95 \% \mathrm{Cls}$. An alpha value of $5 \%$ was considered significant in all analyses. Statistical analysis was carried out on Stata 12 (StataCorp).

\section{Ethics approval and consent to participate}

The survey was approved by the National Research Ethics Service, NRES Committee LondonBromley (REC reference 11/LO/0881). The approval was given as part of a larger study of preconception health and care in England. In accordance with standard practice approved by the research ethics committee, women were consented for the study. 


\section{RESULTS}

\section{Sample Characteristics}

Of 1288 women invited, 1173 were recruited to the study giving a response rate of $91 \%$ (86\%, 91\% and $94 \%$ at each maternity service). Participant characteristics are presented in Table 1 . The mean age was $32 \pm 5$ years, $68 \%$ identified their ethnicity as white, and $66 \%$ had attained at least an undergraduate degree. The mean gestation in weeks (adjusted by due date) at the time this questionnaire was completed was $19.5 \pm 9.6$ weeks. Over half (59\%) had not had a previous live birth, and $30 \%$ had a previous miscarriage, stillbirth or termination. Around a quarter $26 \%$ were currently using medication. Nearly three quarters (73\%) had a London Measure of Unplanned Pregnancy (LMUP) score of 10-12 (planned pregnancy).

\section{Smoking}

\section{Description of smoking patterns}

A total of 1044 participants answered all the questions on smoking patterns. Of these $38 \%$ had never smoked, $45 \%$ reported quitting before pregnancy and $10 \%$ quit during pregnancy at a median gestation of 5 weeks (IQR 4-7). Current cigarette prevalence during pregnancy was $5 \%(95 \% \mathrm{Cl} 3-6 \%)$. Women who continued to smoke $(n=52)$ during pregnancy reduced their intake from a median of 10 cigarettes (IQR 10-15) in the three months preceding pregnancy to a median 4 cigarettes daily (IQR $2-8)$ at the time of the survey $(p<0.001)$. In comparison, women who stopped smoking prepregnancy $(n=110)$ reported smoking half the number of cigarettes daily in the three months before pregnancy (median 5 cigarettes, IQR 3-10) compared with current smokers $(p<0.001)$. Sociodemographic characteristics of smoking patterns are shown in Table 2.

\section{Correlates of smoking patterns}

Correlates of smoking patterns are presented in Table 5. In the unadjusted model, older women, those with higher educational attainment, previous miscarriage, stillbirth or termination, and more planned pregnancy had higher odds of stopping smoking before pregnancy, compared with women who stopped during pregnancy, or were current smokers.

Once adjusted, age remained significant with every one year increase in age being associated with 9\% (95\% 1.04-1.14) increased odds of stopping smoking before pregnancy, compared with women who stopped during pregnancy, or were current smokers. Women who had a previous miscarriage, stillbirth or termination had half the odds of stopping smoking before pregnancy compared with women who stopped during pregnancy, or were current smokers (AOR 0.50, 95\% $\mathrm{Cl} 0.31-0.79$ ), and women with planned pregnancy (LMUP 10-12) had almost four times the odds (AOR 3.82, $95 \% \mathrm{Cl}$ 1.24-11.80).

Less than half of all women recalled receiving smoking-related Healthcare professional (HP) information during pregnancy, with current smokers recalling higher rates $(44 \%$ vs. $73 \%, p<0.001)$. Among women who have ever-smoker, those who received HP information had lower odds of stopping smoking before pregnancy compared to women who didn't receive healthcare input (AOR $0.40,95 \% \mathrm{Cl} 0.25-0.36)^{\prime}$.

\section{Alcohol}

Description of alcohol patterns 
A total of 1042 women answered all the questions on alcohol consumption, of whom $25 \%$ reported having never drank alcohol, $25 \%$ reported quitting pre-pregnancy, $41 \%$ reported quitting during pregnancy (at a median gestation of 4 weeks, IQR $3-6$ ), and $9 \%$ reported being current drinkers.

Current drinkers significantly reduced the number of units consumed from a median of 6 units weekly before pregnancy (IQR 3-10) to 1 unit weekly during pregnancy (IQR 1-2, $p<0.001$ ). When asked to recall the total number of binges (more than 5 drinks in one sitting) during their pregnancy (to include the weeks before they knew then were pregnant), approximately half of current drinkers $(53 \%, n=29)$ recalled a median of 2 binges (IQR 1-4) during their whole pregnancy. Similarly almost half who stopped drinking during pregnancy $(46 \%, n=147)$ also recalled a median of 2 binges (IQR 13). Sociodemographic characteristics of drinking patterns are shown in Table 3.

\section{Correlates of drinking patterns}

In the unadjusted model presented in Table 5, only younger women had lower odds of stopping alcohol consumption before pregnancy, compared with women who stopped during pregnancy, or were current drinkers. In the adjusted model, every one-year increase in age was associated with $4 \%$ (95\% 0.92-1.00) lower odds of stopping alcohol consumption before pregnancy.

Variables associated with higher odds of consumption included lower educational attainment (diploma/A-level vs. Degree, AOR 1.96, 95\% $\mathrm{Cl} 1.23-3.13$ ) and having a more planned pregnancy (LMUP 10-12 vs. LMUP 0-3, AOR 9.71, 95\% Cl 1.18-79.54).

Approximately half of the sample (49\%) recalled receiving alcohol-related HP information during pregnancy. Recall was similar among current alcohol users and those who stopped drinking alcohol during pregnancy ( $61 \%$ cf. $57 \%$ ). Among women who drank alcohol, women who recalled alcoholrelated HP information during pregnancy had no significant odds of current alcohol use compared to those who did not recall-alcohol-related HP information (OR $0.82,95 \% \mathrm{Cl} 0.61-1.10$ ).

\section{Folic acid and multivitamins (supplements)}

\section{Description of supplement use}

Of the 1095 women who answered questions on supplement intake in pregnancy, 62\% ( $n=677$ ) reported currently taking supplements, $18 \%$ (203) were taking supplements during pregnancy but stopped, and $20 \%(n=215)$ never took any supplements during pregnancy. Of those that stopped, women taking folic acid only stopped at a median of 12 weeks (IQR 12-15), in line with national guidance. In comparison, multivitamins are advised throughout pregnancy, but women taking multivitamins alone discontinued at an earlier gestation of 5 weeks (IQR 4-19, $p=0.034$ ).

Among all those who continue to take, or have stopped taking supplements during pregnancy $(n=878)$ the majority $(58 \% n=509)$ took folic acid only, $21 \%(n=184)$ took multivitamins and $21 \%$ ( $n=185$ ) took both. Women reported good compliance with $81 \%$ reporting daily use.

Sociodemographic characteristics of supplement taking patterns are shown in Table 4.

\section{Correlates of supplement intake}

Variables associated with higher odds of current supplement intake, or stopping during pregnancy were age (OR 1.58, 95\% $\mathrm{Cl}$ 1.08-2.30 age 30-34 years cf. $<30$ years) and taking medication (OR 1.75, 95\% $\mathrm{Cl}$ 1.21-2.52 cf. no medication), in comparison to lower educational attainment being associated with lower odds of current supplement intake (OR 0.57, 95\% Cl 0.36-0.89, GCSE/other cf. degree). When adjusted for independent variables the only variable that remained significant was higher odds of current supplement intake when taking medication (AOR 1.51,95\% $\mathrm{Cl} 1.00-2.27$ ). 
Three-quarters of the sample (75\%) recalled receiving supplement related HP information during pregnancy. Compared with women who did not recall supplement related HP information, women who did recall such information had higher odds of currently taking supplements or stopping during pregnancy compared to women who had never taken supplements or stopped pre-pregnancy (OR $1.51,95 \% \mathrm{Cl} 1.09-2.09)$, however this association was no longer statistically significant when adjusted for independent variables.

\section{DISCUSSION}

\section{Main findings}

Overall, women reported improving health behaviours during pregnancy such as reducing or stopping smoking and drinking, and supplement intake. Changes in smoking and drinking behaviours varied by age, ethnicity, educational attainment, and pregnancy planning however these were not always consistent across health behaviours. For example, older age was associated with stopping smoking during pregnancy, but younger age was associated with stopping alcohol during pregnancy, and we did not find age to be associated with supplement intake. Additionally, lower educational attainment was associated with stopping alcohol during pregnancy, but educational attainment was not significantly associated with stopping smoking or supplement intake during pregnancy. Planned pregnancies were more consistently associated with improvements in smoking and drinking health behaviours.

Associations between recall of HP information and health behaviours are not clear-cut, with HP information recall having lower odds of stopping smoking before pregnancy compared with those who didn't recall information, and no significant association was found with other health behaviours in this study. The results are difficult to interpret and may be prone to reverse causality: it is understandable that women who continue to smoke would recall receiving healthcare information, and women who stopped are less likely to recall advice on a stopped behaviour.

\section{Strengths and weaknesses}

The strengths of this study were the large sample of women recruited and the high response rate which may reflect the face-to-face recruitment or long waiting times when attending the maternity services. Recruiting from three maternity services promoted diversity in the sample. Using the London Measure of Unplanned Pregnancy (19) provided a more advanced method of capturing women's preparedness in comparison to the binary questions often used.

Weaknesses included the cross-sectional study design, although no assumptions have been made regarding causality. Data on pre-pregnancy behaviours may have been prone to recall bias, particularly for socially undesirable behaviours such as smoking and drinking, but by recruiting early in pregnancy we aimed to minimise this. Social desirability bias may have resulted in under-reporting of negative health behaviours, and while we cannot fully control for this it was minimised by administering the questionnaire through self-administration without an interviewer(20).

Not all women answered all sections of the questionnaire and we do not know why some sections were unanswered. We can speculate some reasons may include not having sufficient time to complete the questionnaire; the questions not being relevant to them; or they did not want to answer questions on such health behaviours that have a social desirability bias. Although unanswered questions is common to many pen-and-paper questionnaire studies, if the reason was avoidance it may have introduced a selection bias. This may have been mitigated to some extent by the high response rate of $91 \%$ and the self-completion method. 
There was no follow up to ensure whether health behaviours were maintained, however the focus of this study was to report on behaviours in pregnancy, and due to the comparatively short timeframe of pregnancy, they are likely to be an accurate representation. The convenience sampling method may not be representative of target population, and by recruiting in maternity services the likelihood of having received healthcare professional information on specific risk behaviours was increased. However, nearly all pregnant women in the UK attend maternity services at some point during their pregnancy.

\section{Findings in relation to other studies}

A national UK Infant Feeding Survey (8) shows a trend towards lower prevalence of smoking in pregnancy, but the prevalence remains over double the prevalence of current smokers in our sample ( $12 \%$ vs $5 \%$ reported in our study). The Maternity Services Dataset (MSDS) reports a similar prevalence of smoking at booking as $11 \%$ (21). This is most likely a reflection of a relatively high level of pregnancy planning and older age group of women in our study. The Infant Feeding Survey reports similar levels of alcohol consumption during pregnancy ( $40 \%$ vs $41 \%$ reported in our study), and we found similar levels of units consumed between our study and an international multicentre cohort study that includes figures for the UK (22). Similarly, the proportion of women taking supplements is similar in the two studies (8). Other studies in London have found that more women start taking supplements after confirmation of pregnancy, similar to our findings, compared to approximately just a third of women taking supplements pre-pregnancy (23). Folic acid can be prescribed free for all women in the UK, and certain women are advised from their previous pregnancies to take a higher dose if they have had a complication (2).

Sociodemographic disparities are also documented in the Infant Feeding survey and an analysis of the MSDS data which reports strong associations across the UK between smoking, age, and socioeconomic status, remaining broadly similar across all countries in the UK $(8,24)$. They report younger, unemployed mothers tending to be the least likely to quit smoking before or during pregnancy. An association between smoking and education was also noted in the longitudinal Southampton Women's Survey and was found to be consistent throughout pregnancy (25). Our study replicates the association with age, but when adjusted the association with education was lost.

For drinking during pregnancy, the Infant Feeding survey found associations between socioeconomic status and likelihood of drinking before or during pregnancy, as well as a further association between socio-economic status and ethnicity. It found women from ethnic minorities (especially those of an Asian background) being the most likely to have never worked as well as the least likely to drink before or during pregnancy. A multinational European study of alcohol in pregnancy (26) found the highest consumption of alcohol in pregnancy was in the UK, and higher education was a predictor of alcohol consumption during pregnancy. Whilst the association with ethnicity was not replicated in our study, we did find that women of lower educational attainment (diploma/a-level) were more likely than women with a degree to stop drinking before pregnancy rather than stopping drinking during pregnancy, or continuing to drink in pregnancy.

Finally, our study did not show associations between any sociodemographic disparities and supplement intake compared to the Infant Feeding survey which found women under 20 years of age had a less than average likelihood of taking folic acid, and ethnic minorities were less likely to take folic acid than their white counterparts.

Although a much lower rate of unplanned pregnancies was reported in our study compared to the large UK millennium cohort study (3\% reported in our study vs $43 \%,(27)$ this may reflect the older 
age of our sample and advanced method of LMUP to gauge the level of pregnancy planning. Additionally, other UK surveys such as the National Survey of Sexual Attitudes and Lifestyles and a large cohort study in an antenatal and abortion centre in Scotland, both identified that most pregnancies are indeed planned to some degree $(28,29)$.

With regards to HP information, the Infant Feeding survey found that the majority of women recall receiving information on smoking and drinking as described in the introduction (8). A previous study reported on this questionnaire (11) found that over half of all women reported advice from a health professional before becoming pregnant and showed a dose dependent associations between health professional information and pre-pregnancy behaviour changes including: cutting smoking, alcohol, changing to a healthier diet, and taking folic acid supplements. When adjusted the association remained significant for taking folic acid and changing to a healthier diet.

The nature of antenatal care in the UK would mean women are regularly exposed to HPs providing, multiple opportunities for advice which would explain the higher odds of recall in women who were current smokers, as they are more likely to get repeated information at regular encounters if they continue smoking during pregnancy.

It is unsurprising that the reduction of, or abstaining from, a behaviour is multifactorial and further complicated by the addictive properties of some negative health behaviours (30). HP's awareness of individual women's social situation and consequently tailoring of their advice may increase effectiveness of HP information provided to women through a mutually respectful dialogue (31). Wider implications and future research

Understanding how certain health behaviours change during pregnancy allows better targeted public health intervention. An attempt to develop a more robust prevalence estimate for smoking during pregnancy by comparing primary care data to national figures (32) found the estimates to be unreliable due to under-recording of smoking status during pregnancy in primary care data. Other studies, such as one conducted in the United States which developed maternal smoking and cessation prevalence estimates for before and during pregnancy from $95 \%$ of birth certificates issued in 2003 (33), can provide good points of reference but they are quickly outdated.

In the UK progress has been made with the publication of the MSDS, however there remains concerns over data quality, with poor recording of key information an ongoing issue (21). This data set also obtains the majority of its health behaviour data from the booking episode, limiting our awareness of how to target tailored interventions during pregnancy. Our previous research in the UK showed that awareness of the importance of preconception health among women and health professionals is low and responsibility for providing preconception care unclear (11). In practice, women seldom volunteer their intention to become pregnant and health professionals seldom ask about this, even in sexual and reproductive health services. Hence a key opportunity to improve maternal and child health continues to be missed.

The documented associations with sociodemographic disparities also found in our study highlight the need for all evaluations or future work to take these into account. Such work is already occurring, with 'healthy start' vitamins made freely available to pregnant women who are under the age of 18 years or entitled to benefits in the UK (34), however further work is needed, as uptake is generally poor.

\section{CONCLUSIONS}

In conclusion, women are improving their health behaviours during, and in preparation for pregnancy and an appreciation of that is important, as well as the continued health professional 
advice and guidance on desirable health behaviours to women during pregnancy. Beyond this, increased data records and innovative methods for preconception care is needed to improve maternal health further. 
Table 1: Characteristics of sample, $\%$ (n)

\begin{tabular}{|c|c|}
\hline Characteristics & All women \\
\hline Total & $100(1173)$ \\
\hline \multicolumn{2}{|l|}{ Age (years) } \\
\hline$<30$ & $28(288)$ \\
\hline $30-34$ & $41(419)$ \\
\hline $35+$ & $31(324)$ \\
\hline \multicolumn{2}{|l|}{ Ethnic group } \\
\hline White & $68(705)$ \\
\hline Non-White & $32(338)$ \\
\hline \multicolumn{2}{|l|}{ Educational attainment } \\
\hline Degree & $66(682)$ \\
\hline Diploma/A-level & 18(183) \\
\hline GCSE/Other & 13(133) \\
\hline No qualifications & $3(30)$ \\
\hline \multicolumn{2}{|l|}{ Previous live birth } \\
\hline No & $59(607)$ \\
\hline Yes & $41(428)$ \\
\hline \multicolumn{2}{|l|}{ Taking medication } \\
\hline No & $74(863)$ \\
\hline Yes & $26(310)$ \\
\hline \multicolumn{2}{|l|}{ Previous miscarriage, stillbirth or termination } \\
\hline No & $70(65)$ \\
\hline Yes & $30(279)$ \\
\hline \multicolumn{2}{|l|}{ LMUP score } \\
\hline Unplanned (0-3) & $3(36)$ \\
\hline Ambivalent (4-9) & $24(272)$ \\
\hline Planned (10-12) & $73(840)$ \\
\hline
\end{tabular}


Table 2: Characteristics of sample, stratified by smoking status, \% ( $n$ )

*Total refers to women who answered questions on smoking

\begin{tabular}{|c|c|c|c|c|}
\hline Characteristics & Never smoked & $\begin{array}{l}\text { Quit pre- } \\
\text { pregnancy }\end{array}$ & $\begin{array}{l}\text { Quit during } \\
\text { pregnancy }\end{array}$ & Current smoker \\
\hline $100(1044)$ & $38(400)$ & 45 (482) & $10(110)$ & $5(52)$ \\
\hline Age (years) & & & $p=0.001$ & \\
\hline$<30$ & $31(111)$ & $23(106)$ & $38(38)$ & $44(21)$ \\
\hline $30-34$ & $38(138)$ & $43(197)$ & $44(44)$ & $27(13)$ \\
\hline $35+$ & $31(114)$ & $34(156)$ & 19(19) & $29(14)$ \\
\hline \multicolumn{5}{|l|}{ Ethnic group } \\
\hline White & $65(241)$ & $67(309)$ & $74(73)$ & $68(32)$ \\
\hline Non-White & $35(132)$ & $33(155)$ & $26(26)$ & $32(15)$ \\
\hline Educational attainment & $p<0.0001$ & & & \\
\hline Degree & $73(266)$ & $68(315)$ & $50(49)$ & $36(15)$ \\
\hline Diploma/A-level & $13(49)$ & 19(86) & $26(26)$ & $31(13)$ \\
\hline GCSE/Other & $11(41)$ & $10(48)$ & $22(22)$ & $26(11)$ \\
\hline No qualifications & $3(10)$ & $3(13)$ & $2(2)$ & $7(3)$ \\
\hline \multicolumn{5}{|l|}{ Previous live birth } \\
\hline No & $43(205)$ & $52(271)$ & $57(64)$ & $48(27)$ \\
\hline Yes & $44(160)$ & $42(195)$ & $35(34)$ & $44(21)$ \\
\hline \multicolumn{5}{|l|}{ Taking medication } \\
\hline No & $70(280)$ & $72(364)$ & $78(86)$ & $75(39)$ \\
\hline Yes & $30(120)$ & $28(140)$ & $22(24)$ & $25(13)$ \\
\hline $\begin{array}{l}\text { Previous miscarriage, } \\
\text { stillbirth or termination }\end{array}$ & & & & $p=0.002$ \\
\hline No & $72(242)$ & $72(300)$ & $63(56)$ & $46(19)$ \\
\hline Yes & $28(92)$ & $27(114)$ & $36(32)$ & $54(22)$ \\
\hline LMUP score & & & $p<0.0001$ & $p<0.0001$ \\
\hline Unplanned (0-3) & $2(6)$ & $3(15)$ & $7(8)$ & $4(2)$ \\
\hline Ambivalent (4-9) & $24(93)$ & $16(82)$ & $47(52)$ & $50(26)$ \\
\hline Planned (10-12) & $75(296)$ & $81(405)$ & $44(50)$ & $46(24)$ \\
\hline $\begin{array}{l}\text { Healthcare Professional } \\
\text { information on Smoking }\end{array}$ & & & & $p<0.0001$ \\
\hline No & $63(252)$ & $57(25)$ & $41(45)$ & $27(14)$ \\
\hline Yes & $37(148)$ & $43(219)$ & $59(65)$ & $73(38)$ \\
\hline
\end{tabular}


Table 3: Characteristics of sample, stratified by alcohol consumption status, \% ( $n$ )

*Total refers to women who answered questions on alcohol

\begin{tabular}{|c|c|c|c|c|}
\hline Characteristics & $\begin{array}{l}\text { Never had } \\
\text { Alcohol }\end{array}$ & $\begin{array}{l}\text { Quit pre- } \\
\text { pregnancy }\end{array}$ & $\begin{array}{l}\text { Quit during } \\
\text { pregnancy }\end{array}$ & Current drinker \\
\hline $100(1045)$ & $25(265)$ & $25(257)$ & $41(425)$ & 9 (98) \\
\hline Age (years) & & & & $p<0.001$ \\
\hline$<30$ & $50(116)$ & $26(59)$ & 19(76) & $15(14)$ \\
\hline $30-34$ & $29(67)$ & $41(92)$ & $47(189)$ & 49(47) \\
\hline $35+$ & $22(51)$ & $33(76)$ & $34(139)$ & $36(35)$ \\
\hline Ethnic group & $p<0.001$ & $p<0.001$ & $p<0.001$ & \\
\hline White & $38(90)$ & $73(170)$ & 78(320) & $81(78)$ \\
\hline Non-White & 62(147) & $27(62)$ & $22(88)$ & 19(18) \\
\hline Educational attainment & $p<0.001$ & $p<0.001$ & $p<0.001$ & \\
\hline Degree & $52(120)$ & $65(151)$ & 74(300) & $76(71)$ \\
\hline Diploma/A-level & $23(52)$ & $21(49)$ & $14(59)$ & $12(11)$ \\
\hline GCSE/Other & $17(39)$ & $13(30)$ & $11(43)$ & 10(9) \\
\hline No qualifications & $8(18)$ & $2(4)$ & $1(6)$ & $2(2)$ \\
\hline Previous live birth & & & & $p<0.001$ \\
\hline No & $48(110)$ & $62(148)$ & $65(264)$ & $50(47)$ \\
\hline Yes & $52(120)$ & $38(91)$ & $35(141)$ & $50(47)$ \\
\hline \multicolumn{5}{|l|}{ Taking medication } \\
\hline No & $80(211)$ & $83(187)$ & $68(291)$ & $67(66)$ \\
\hline Yes & $20(54)$ & $27(70)$ & $32(134)$ & $33(32)$ \\
\hline \multicolumn{5}{|l|}{$\begin{array}{l}\text { Previous miscarriage, } \\
\text { stillbirth or termination }\end{array}$} \\
\hline No & $67(129)$ & 70(156) & $72(272)$ & $73(62)$ \\
\hline Yes & $33(64)$ & $30(66)$ & $28(105)$ & $27(23)$ \\
\hline LMUP score & & & & $p=0.001$ \\
\hline Unplanned (0-3) & $5(12)$ & $2(4)$ & $3(14)$ & $0(0)$ \\
\hline Ambivalent (4-9) & $28(72)$ & $15(39)$ & $25(106)$ & $30(29)$ \\
\hline Planned (10-12) & $68(178)$ & $83(213)$ & 712302) & 70(69) \\
\hline $\begin{array}{l}\text { Healthcare Professional } \\
\text { information on Alcohol }\end{array}$ & $p<0.001$ & $p<0.001$ & $p<0.001$ & \\
\hline No & 72(191) & $47(121)$ & 43(183) & $39(38)$ \\
\hline Yes & $28(74)$ & 33(136) & $57(242)$ & $61(60)$ \\
\hline
\end{tabular}


Table 4: Characteristics of sample, stratified by supplement consumption status, \% (n)

* Total refers to women who answered questions on supplement intake

\begin{tabular}{|c|c|c|c|}
\hline Characteristics & $\begin{array}{l}\text { Never had } \\
\text { supplements }\end{array}$ & $\begin{array}{l}\text { Stopped taking } \\
\text { during pregnancy }\end{array}$ & $\begin{array}{l}\text { Currently takes } \\
\text { supplements }\end{array}$ \\
\hline $\begin{array}{l}\text { Total* } \\
\text { 100(1095) }\end{array}$ & $18(215)$ & $18(203)$ & $62(677)$ \\
\hline Age (years) & & & $p<0.001$ \\
\hline$<30$ & $34(67)$ & $36(68)$ & 24 (148) \\
\hline $30-34$ & $34(68)$ & $41(78)$ & $43(268)$ \\
\hline $35+$ & $32(63)$ & $23(44)$ & $33(210)$ \\
\hline \multicolumn{4}{|l|}{ Ethnic group } \\
\hline White & $65(126)$ & $65(126)$ & $69(442)$ \\
\hline Non-White & $35(69)$ & $35(67)$ & 31 (195) \\
\hline Educational attainment & & & $p<0.0001$ \\
\hline Degree & $58(109)$ & 55 (108) & $72(457)$ \\
\hline Diploma/A-level & 21 (39) & $22(43)$ & $16(98)$ \\
\hline GCSE/Other & $18(33)$ & $20(38)$ & $9(59)$ \\
\hline No qualifications & $3(6)$ & $3(6)$ & $3(17)$ \\
\hline \multicolumn{4}{|l|}{ Previous live birth } \\
\hline No & 56 (109) & 54 (105) & $61(382)$ \\
\hline Yes & $44(85)$ & $46(89)$ & 39 (248) \\
\hline Taking medication & & & $p<0.0001$ \\
\hline No & $80(173)$ & $77(157)$ & $68(461)$ \\
\hline Yes & $20(42)$ & $23(46)$ & $32(216)$ \\
\hline \multicolumn{4}{|l|}{$\begin{array}{l}\text { Previous miscarriage, } \\
\text { stillbirth or termination }\end{array}$} \\
\hline No & $69(114)$ & $73(130)$ & 69 (398) \\
\hline Yes & $31(51)$ & $27(49)$ & 31 (176) \\
\hline LMUP score & & & $p<0.0001$ \\
\hline Unplanned (0-3) & $6(13)$ & $3(6)$ & $2(12)$ \\
\hline Ambivalent (4-9) & $34(72)$ & $24(49)$ & 21 (139) \\
\hline Planned (10-12) & 60 (129) & 73 (146) & $77(522)$ \\
\hline $\begin{array}{l}\text { Healthcare Professional } \\
\text { information on } \\
\text { supplement taking }\end{array}$ & & & $p=0.007$ \\
\hline No & $32(69)$ & $19(38)$ & $25(172)$ \\
\hline Yes & $68(146)$ & $81(165)$ & $75(505)$ \\
\hline
\end{tabular}




\begin{tabular}{|c|c|c|c|}
\hline Exposure & $\begin{array}{l}\text { Odds of exposure in } \\
\text { women who stopped } \\
\text { smoking before } \\
\text { pregnancy relative to } \\
\text { all others* } \\
\text { OR (CI) }\end{array}$ & $\begin{array}{l}\text { Odds of exposure in } \\
\text { women who stopped } \\
\text { drinking alcohol } \\
\text { before pregnancy } \\
\text { relative to all others* } \\
\text { OR (CI) }\end{array}$ & $\begin{array}{l}\text { Comparing women } \\
\text { taking supplements as } \\
\text { per } \\
\text { recommendations** } \\
\text { to women who did not } \\
\text { OR }(\mathrm{Cl})\end{array}$ \\
\hline \multicolumn{4}{|l|}{ Age (years) } \\
\hline$<30$ & $1-$ & 1- & 1- \\
\hline $30-34$ & $\begin{array}{l}1.92(1.25-2.97) \\
p=0.003\end{array}$ & $\begin{array}{l}0.59(0.40-0.89) \\
p=0.012\end{array}$ & $\begin{array}{l}1.58(1.08-2.30) \\
p=0.018\end{array}$ \\
\hline $35+$ & $\begin{array}{l}2.63(1.61-4.30) \\
p<0.001\end{array}$ & $0.67(0.44-1.02)$ & $1.25(0.85-1.85)$ \\
\hline \multicolumn{4}{|l|}{ Ethnic group } \\
\hline White & $0.78(0.52-1.17)$ & $0.73(0.51-1.05)$ & $1.19(0.86-1.65)$ \\
\hline Non-White & $1-$ & 1- & 1- \\
\hline \multicolumn{4}{|c|}{ Educational attainment } \\
\hline Degree & $1-$ & $1-$ & 1- \\
\hline Diploma/A-level & $\begin{array}{l}0.45(0.28-0.71) \\
p=0.001\end{array}$ & $\begin{array}{l}1.72(1.14-2.59) \\
p=0.01\end{array}$ & $0.70(0.46-1.05)$ \\
\hline GCSE/Other & $\begin{array}{l}0.30(0.18-0.50) \\
p<0.0001\end{array}$ & $1.42(0.87-2.31)$ & $\begin{array}{l}0.57(0.36-0.89) \\
p=0.012\end{array}$ \\
\hline No qualifications & $0.53(0.18-1.53)$ & $1.23(0.36-4.14)$ & $0.74(0.29-1.86)$ \\
\hline \multicolumn{4}{|l|}{ Previous live birth } \\
\hline No & 1- & 1- & 1- \\
\hline Yes & $1.19(0.81-1.74)$ & $1.02(0.74-1.40)$ & $0.89(0.65-1.22)$ \\
\hline \multicolumn{4}{|l|}{ Taking medication } \\
\hline No & $1-$ & 1- & 1- \\
\hline Yes & $1.30(0.86-1.97)$ & $0.81(0.58-1.12)$ & $\begin{array}{l}1.75(1.21-2.52) \\
p=0.003\end{array}$ \\
\hline \multicolumn{4}{|l|}{$\begin{array}{l}\text { Previous miscarriage, } \\
\text { stillbirth or termination }\end{array}$} \\
\hline No & $1-$ & 1- & 1- \\
\hline Yes & $\begin{array}{l}0.53(0.35-0.80) \\
p<0.0001\end{array}$ & $1.10(0.78-1.57)$ & $0.95(0.66-1.37)$ \\
\hline \multicolumn{4}{|c|}{ LMUP score } \\
\hline Unplanned (0-3) & 1- & 1- & 1- \\
\hline Ambivalent (4-9) & $0.70(0.30-1.65)$ & $1.01(0.31-3.25)$ & $1.88(0.88-4.05)$ \\
\hline Planned (10-12) & $\begin{array}{l}3.65(1.58-8.43) \\
p=0.002\end{array}$ & $2.01(0.31-3.25)$ & $\begin{array}{l}3.74(1.79-7.82) \\
p<0.0001\end{array}$ \\
\hline \multicolumn{4}{|c|}{$\begin{array}{r}\text { Received healthcare } \\
\text { professional information }\end{array}$} \\
\hline No & 1- & 1- & 1- \\
\hline Yes & $\begin{array}{l}0.44(0.31-0.63) \\
p<0.0001\end{array}$ & $0.82(0.61-1.10)$ & $\begin{array}{l}1.51(1.09-2.09) \\
p=0.013\end{array}$ \\
\hline
\end{tabular}

Table 5: Correlates of smoking, alcohol consumption, and supplement intake status

\footnotetext{
*Others includes those who stopped the behaviour during pregnancy, or continued the behaviour in pregnancy.

** The recommendations are as follows: women are recommended to continue folic acid until 12 weeks of pregnancy, and continue multivitamin intake throughout their pregnancy.
} 



\section{ACKNOWLEDGEMENTS}

We thank all the women and health professionals who took part in the study. We thank the project team and steering group.

\section{FUNDING}

The study was funded by the Policy Research Programme of the Department of Health. http://www.prp-ccf.org.uk. The PRP Reference number for the project is 006/0068. The funders had no role in study design, data collection, and analysis

\section{REFERENCES}

1. Salihu HM, Wilson RE. Epidemiology of prenatal smoking and perinatal outcomes. Early Hum Dev. 2007;83.

2. NHS Choices. Pregnancy and Baby (online) 2016 [07/04/2016]. Available from: http://www.nhs.uk/Conditions/pregnancy-and-baby.

3. Department of Health. UK chief medical officers' alcohol guidelines review: summary of the proposed new guidelines. January 2016 [07/04/2016]. Available from: https://www.gov.uk/government/consultations/health-risks-from-alcohol-new-guidelines.

4. Patra J, Bakker R, Irving H, Jaddoe VWV, Malini S, Rehm J. Dose-response relationship between alcohol consumption before and during pregnancy and the risks of low birthweight, preterm birth and small for gestational age (SGA) - a systematic review and meta-analyses. BJOG: An International Journal of Obstetrics \& Gynaecology. 2011;118(12):1411-21.

5. Fekete K, Berti C, Trovato M, Lohner S, Dullemeijer C, Souverein OW, et al. Effect of folate intake on health outcomes in pregnancy: a systematic review and meta-analysis on birth weight, placental weight and length of gestation. Nutrition Journal. 2012;11(1):1-8.

6. Goh YI, Bollano E, Einarson TR, Koren G. Prenatal multivitamin supplementation and rates of congenital anomalies: a meta-analysis. Journal of obstetrics and gynaecology Canada : JOGC = Journal d'obstetrique et gynecologie du Canada : JOGC. 2006 Aug;28(8):680-9. PubMed PMID: 17022907. Epub 2006/10/07. eng.

7. Goh YI, Bollano E, Einarson TR, Koren G. Prenatal multivitamin supplementation and rates of pediatric cancers: a meta-analysis. Clinical pharmacology and therapeutics. 2007 May;81(5):685-91. PubMed PMID: 17314929. Epub 2007/02/23. eng.

8. McAndrew F, Thompson J, Fellows L, Large A, Speed M, Renfrew MJ. Infant feeding survey 2010. Leeds: Health and Social Care Information Centre. 2012.

9. Robbins JM, Cleves MA, Collins HB, Andrews N, Smith LN, Hobbs CA. Randomized trial of a physician-based intervention to increase the use of folic acid supplements among women. American journal of obstetrics and gynecology. 2005 Apr;192(4):1126-32. PubMed PMID: 15846191. Epub 2005/04/23. eng.

10. Mottillo S, Filion KB, Bélisle P, Joseph L, Gervais A, O'Loughlin J, et al. Behavioural interventions for smoking cessation: a meta-analysis of randomized controlled trials. European Heart Journal. 2009 2009-03-01 00:00:00;30(6):718-30.

11. Stephenson J, Patel D, Barrett G, Howden B, Copas A, Ojukwu O, et al. How do women prepare for pregnancy? Preconception experiences of women attending antenatal services and views of health professionals. PLoS One. 2014;9(7):e103085.

12. Ebert LM, Fahy K. Why do women continue to smoke in pregnancy? Women and Birth 2007.20(4):161-8.

13. NHS Digital. Maternity Services Data Set [Accessed on 31/07/2019 at https://bit.ly/2OvfVc3]. 2019.

14. Barrett G, Smith SC, Wellings K. Conceptualisation, development, and evaluation of a measure of unplanned pregnancy. Journal of Epidemiology \& Community Health. 2004;58(5):42633. 
15. Wellings $\mathrm{K}$, Jones KG, Mercer $\mathrm{CH}$, Tanton C, Clifton S, Datta J, et al. The prevalence of unplanned pregnancy and associated factors in Britain: findings from the third National Survey of Sexual Attitudes and Lifestyles (Natsal-3). The Lancet. 2013;382(9907):1807-16.

16. Barrett G, Shawe J, Howden B, Patel D, Ojukwu O, Pandya P, et al. Why do women invest in pre-pregnancy health and care? A qualitative investigation with women attending maternity services. BMC Pregnancy and Childbirth. 2015;15(1):236.

17. Inskip HM, Godfrey KM, Robinson SM, Law CM, Barker DJ, Cooper C. Cohort profile: The Southampton Women's Survey. Int J Epidemiol. 2006 Feb;35(1):42-8. PubMed PMID: 16195252. Pubmed Central PMCID: PMC4579566. Epub 2005/10/01. eng.

18. Stern J, Larsson $M$, Kristiansson $P$, Tyden $T$. Introducing reproductive life plan-based information in contraceptive counselling: an RCT. Human reproduction (Oxford, England). 2013 Sep;28(9):2450-61. PubMed PMID: 23842564. Pubmed Central PMCID: PMC3748861. Epub 2013/07/12. eng.

19. Barrett G, Smith SC, Wellings K. Conceptualisation, development, and evaluation of a measure of unplanned pregnancy. J Epidemiol Community Health. 2004 May;58(5):426-33. PubMed PMID: 15082745. Pubmed Central PMCID: PMC1732751. Epub 2004/04/15. eng.

20. Grimm P. Social Desirability Bias. Wiley International Encyclopedia of Marketing2010.

21. Public Health England. Health of women before and during pregnancy: health behaviours, risk factors and inequalities. An initial analysis of the Maternity Services Dataset antenatal booking data. [Accessed on 31/07/2019 at https://bit.ly/2mRHSdy]. 2018.

22. O'Keeffe LM, Kearney PM, McCarthy FP, Khashan AS, Greene RA, North RA, et al. Prevalence and predictors of alcohol use during pregnancy: findings from international multicentre cohort studies. BMJ Open. 2015 May 1, 2015;5(7).

23. Bestwick JP, Huttly WJ, Morris JK, Wald NJ. Prevention of Neural Tube Defects: A CrossSectional Study of the Uptake of Folic Acid Supplementation in Nearly Half a Million Women. PLoS ONE. 2014;9(2):e89354.

24. Stephenson J, Vogel C, Hall J, Hutchinson J, Mann S, Duncan H, et al. Preconception health in England: a proposal for annual reporting with core metrics. The Lancet. 2019;393(10187):226271.

25. Crozier SR, Robinson SM, Borland SE, Godfrey KM, Cooper C, Inskip HM, et al. Do women change their health behaviours in pregnancy? Findings from the Southampton Women's Survey. Paediatric and perinatal epidemiology. 2009;23(5):446-53. PubMed PMID: PMC3091015.

26. Mårdby A-C, Lupattelli A, Hensing G, Nordeng H. Consumption of alcohol during pregnancy-A multinational European study. Women and Birth. 2017.

27. Flower A, Shawe J, Stephenson J, Doyle P. Pregnancy planning, smoking behaviour during pregnancy, and neonatal outcome: UK millennium cohort study. BMC Pregnancy and Childbirth. 2013;13(1):1-7.

28. Wellings K, Jones KG, Mercer CH, Tanton C, Clifton S, Datta J, et al. The prevalence of unplanned pregnancy and associated factors in Britain: findings from the third National Survey of Sexual Attitudes and Lifestyles (Natsal-3). The Lancet.382(9907):1807-16.

29. Lakha F, Glasier A. Unintended pregnancy and use of emergency contraception among a large cohort of women attending for antenatal care or abortion in Scotland. The Lancet.368(9549):1782-7.

30. Niaura RS, Rohsenow DJ, Binkoff JA, Monti PM, Pedraza M, Abrams DB. Relevance of cue reactivity to understanding alcohol and smoking relapse. Journal of abnormal psychology. 1988;97(2):133.

31. Ebert LM, Fahy K. Why do women continue to smoke in pregnancy? Women and Birth. 2007 2007/12/01/;20(4):161-8.

32. Dhalwani NN, Tata L, Coleman T, Fiaschi L, Szatkowski L. A comparison of UK primary care data with other national data sources for monitoring the prevalence of smoking during pregnancy. 
J Public Health (Oxf). 2015 Sep;37(3):547-54. PubMed PMID: 25336275. Pubmed Central PMCID: PMC4552009. Epub 2014/10/23. eng.

33. Curtin S, Matthews T. Smoking Prevalence and Cessation Before and During Pregnancy: Data From the Birth Certificate, 2014. National vital statistics reports: from the Centers for Disease Control and Prevention, National Center for Health Statistics, National Vital Statistics System. 2016;65(1):1-14.

34. Healthy Start Vitamins: Department of Health; 2017 [04/03/2017]. Available from: https://www.healthystart.nhs.uk/healthy-start-vouchers/healthy-start-vitamins/. 